\title{
Una aproximación descriptiva a la desigualdad socio-territorial en ámbitos rurales del Noroeste Argentino en la primera década del siglo XXI
}

\section{A descriptive approach to the social and territorial inequality in rural areas of Northwest Argentina in the first decade of the XXI century}

\author{
Julieta Krapovickas ${ }^{1}$, Ana Garay ${ }^{2}$
}

\begin{abstract}
RESUMEN
A partir de las últimas décadas del siglo XX, el sector rural del Noroeste Argentino fue escenario de profundas transformaciones territoriales y productivas ligadas a la expansión de actividades extractivas. Los efectos de estas actividades incluyen acaparamientos, privatización y concentración de tierras, generando un aumento de la desigualdad socio-territorial. El objetivo de este trabajo es, pues, analizar la desigualdad socio-territorial en las áreas rurales del Noroeste Argentino en la primera década del siglo XXI. Se analizaron fundamentalmente cuatro dimensiones: pobreza, educación, calidad del hábitat y estructura agraria. Para el análisis de las tres primeras dimensiones se utilizaron datos provenientes de los censos nacionales de población 2001 y 2010, y de la Dirección de Estadísticas e Información en Salud. Para el análisis de las transformaciones territoriales y productivas se utilizaron datos de los censos nacionales agropecuarios 1988, 2002 y 2008, y del sistema integrado de información agrope-
\end{abstract}

1 Consejo de Investigaciones Científicas y Técnicas (CONICET), Instituto Superior de Estudios Sociales (CONICET - UNT) krapovickasjulieta@gmail.com ORCID iD: http://orcid. org/0000-0002-1247-3994

2 Consejo de Investigaciones Científicas y Técnicas (CONICET), Instituto Superior de Estudios Sociales (CONICET - UNT) la_garay@hotmail.com ORCID iD: http://orcid.org/00000003-4517-5093

Copyright: @ 2017 CSIC. Este es un artículo de acceso abierto distribuido bajo los términos de la licencia de uso y distribución Creative Commons Attribution (CC-by) España 3.0. 
cuaria. Los resultados nos permiten observar que, mientras las dimensiones educación y calidad del hábitat mejoraron durante la primera década del siglo XXI, aún persisten condiciones de alta pobreza y vulnerabilidad, en un contexto de una estructura agraria progresivamente desigual.

Palabras clave: desigualdad; pobreza; noroeste argentino; extractivismo; territorio.

Abstract

From the last decades of the twentieth century, the rural sector of the Argentine Northwest was the scene of deep territorial and productive transformations linked to the expansion of extractive activities. The effects of these activities include privatization, concentration and land grabs, generating an increase of social and territorial inequality. The aim of this paper is therefore to analyze the socio-territorial inequality in rural areas of Northwest Argentina in the first decade of the XXI century. Four dimensions were analyzed: poverty, education, habitat quality, and agrarian structure. For the analysis of the first three dimensions, data from national population census 2001 and 2010 were used. For the analysis of the territorial and productive transformations were used data from national agricultural censuses 1988, 2002 and 2008. The results allow us to observe that while the habitat quality and education improved during the first decade of the century, there are high poverty and vulnerability in a context of a progressively unequal agrarian structure.

KEY WORDS: inequality; poverty; Northwest Argentina; extractivism; territory.

Cómo citar este artículo/Citation: Krapovickas, Julieta, Garay, Ana (2017): "Una aproximación descriptiva a la desigualdad socio-territorial en ámbitos rurales del Noroeste Argentino en la primera década del siglo XXI", Estudios Geográficos, LXXVIII/283, pp. 605-632

\section{INTRODUCCIÓN}

Desde las últimas décadas del siglo XX, el sector rural del Noroeste Argentino (NOA) viene siendo el escenario de profundas transformaciones productivas ligadas a la expansión de las actividades económicas intensivas en el uso de capital (Bolsi et al., 2006), que pueden caracterizarse como extractivas (Giarracca y Teubal, 2010). Entre ellas podemos mencionar: la agricultura para exportación (por ejemplo soja, citrus, olivos), la vitivinicultura y la mega-minería (Paolasso et al., 2013). En todas estas actividades productivas capital-intensivas, los procesos de acaparamiento, privatización y concentración de la tierra son particularmente visibles (Rivas y Natera-Rivas, 2009), lo cual profundiza las ya históricas desigualdades 
socio-territoriales (Göbel et al., 2014). La progresiva descampesinización de los territorios rurales ( $\mathrm{Paz}, 2006)$, la emergencia y proliferación de villas miseria $^{3}$ en los pueblos, la escasez de alternativas productivas viables, la presión sobre la tierra y la emigración rural son evidencias claras de estos procesos en las áreas rurales del NOA (Bolsi, 2004).

A pesar de la extendida literatura sobre estos procesos en el NOA, todavía es necesario profundizar el análisis sobre las desigualdades en los espacios rurales para dar cuenta, a través de datos empíricos, de los efectos sociales y poblacionales del modelo productivo en curso. Es por esto, que en este trabajo planteamos como objetivo describir algunos indicadores que nos permitan visibilizar esta desigualdad socio-territorial en las áreas rurales del NOA en la primera década del siglo XXI.

A escala nacional se han realizado ya algunas aproximaciones que dan cuenta de las principales tendencias. Los trabajos, por ejemplo de Longhi et al. (2013), Paolasso et al. (2014) y Velázquez y Mesaros (2015), que analizan la distribución en el territorio argentino de las condiciones de bienestar y pobreza, son coincidentes con otros análisis más sociológicos como los de Kessler (2014) y Salvia (2011), quienes demuestran la permanencia, durante la primera década del siglo XXI, de los niveles de desigualdad entre las regiones argentinas. Es preciso entonces preguntarse cómo y porqué la desigualdad persiste y/o se incrementa bajo escenarios de importante generación de riquezas y alto crecimiento económico como el que experimentó Argentina entre 2003 y 2010.

Recordemos que durante la primera década de este siglo, Argentina se recuperó de una de las peores crisis económicas de su historia. El papel del Estado en esta recuperación económica fue muy importante, controlando el mercado de cambios, ampliando subsidios, jubilaciones y ayudas sociales ${ }^{4}$. Sin embargo, y a pesar de estas políticas tendientes a la redistribución de los ingresos, las fuentes de riqueza no se han distribuido equitativamente, es decir, la base estructural de la riqueza sigue intacta ya que no se han puesto en cuestión los modelos económicos que generan desigualdad. Ni la tierra, ni los medios de producción de riqueza, como la banca, se han distribuido. En efecto, una base importante del crecimiento económico y de los ingresos del

3 Las Villas miseria, villas de emergencia o simplemente villas, son los formas de nombrar a los asentamientos informales no planificados en Argentina. En Brasil se las conoce como favelas y en Chile como campamentos.

4 Por ejemplo numerosos trabajos dan cuenta de la importancia de la aplicación de la Asignación Universal por Hijo para reducir la pobreza extrema entre los grupos más vulnerables (ver Agis et al., 2010 y Gasparini y Cruces, 2010). 
Estado argentino sigue siendo (como lo ha sido históricamente) la explotación y la exportación de recursos naturales, fortaleciendo el modelo económico imperante en las décadas de mayor auge de neoliberalismo económico. En este sentido, podemos hablar de un nuevo boom extractivista en Argentina con efectos sociales y territoriales que, pese a las medidas paliativas, no logran revertir la desigualdad.

\section{AproXimaCiOnes teÓRICAS Y DECISIONES METODOLÓGICAS}

\subsection{El desarrollo geográfico desigual y el extractivismo}

Los desarrollos teóricos y las conceptualizaciones sobre las consecuencias sociales y territoriales de la globalización son aportes muy importantes para nuestro trabajo. Particularmente el enfoque del desarrollo geográfico desigual, desarrollado por Harvey (2003). Para este autor, el proceso de globalización es un proceso de desarrollo temporal y geográfico desigual. Las diferencias geográficas, resultantes de legados históricos y geográficos, se sostienen y reproducen por los procesos político-económicos y socio-ecológicos que tienen lugar en el presente, adquiriendo gran relevancia a partir de la consolidación de los procesos de globalización económica, política y cultural. Estos procesos ponen de manifiesto la vulnerabilidad selectiva que expone de manera desigual a las poblaciones a efectos tales como el desempleo, la degradación de los niveles de vida y la pérdida de recursos, de opciones y de calidades ambientales, así como al mismo tiempo «concentra la riqueza y el poder y más oportunidades políticas y económicas en unas cuantas localizaciones selectivas y dentro de unos cuantos estratos restringidos de población» (Harvey, 2003:102). En sintonía, Bauman (2008) observa que los procesos globalizadores carecen de esa unidad de efectos que, generalmente, se da por sentada. En este sentido, afirma que la globalización divide en la misma medida que une: «lejos de homogeneizar la condición humana, la anulación tecnológica de las distancias de tiempo y espacio tiende a polarizarla» (2008:28). Emancipa a ciertos humanos de las restricciones territoriales a la vez que despoja al territorio, donde otros permanecen confinados, de su valor y su capacidad para otorgar identidad.

Otro enfoque muy importante para el análisis de los efectos sociales, demográficos y territoriales de los procesos globalizadores en los espacios rurales argentinos es el del extractivismo. Norma Giarracca y Miguel Teubal presentaron las principales características del modelo extractivista, 
argumentando que no cualquier actividad industrial o agraria es extractiva sino que, en general, se caracterizan por presentar una serie de rasgos que incluyen: 1) tienen un alto consumo de recursos que no son reproducibles (como por ejemplo el agua); 2) las escalas de producción son enormes, desplazando actividades preexistentes; 3) utilizan tecnología de punta; 4) se localizan en lugares con recursos naturales estratégicos; 5) generan mucho valor de cambio y grandes rentabilidades para algunos agentes económicos, pero muy poco valor de uso para la comunidad; 6) se trata de actividades impulsadas por grandes corporaciones; 7) desplazan masivamente tanto a trabajadores rurales, al campesinado y a la agroindustria como a las poblaciones circundantes; 8) se orientan a exportaciones, es decir, no contribuyen a resolver necesidades internas, y no son esenciales para la vida de las comunidades; 9) son altamente conflictivas respecto de las tradicionales actividades existentes en la zona; 10) están relacionadas con la generación y apropiación de rentas de los recursos naturales (Giarracca y Teubal, 2010).

Otro aspecto a tener en cuenta en relación al modelo extractivista es el rol de los estados progresistas latinoamericanos. Eduardo Gudynas (2012) advierte sobre el activo papel de los estados, quienes mantienen, alientan y hasta subvencionan una estrategia extractivista mientras que, al mismo tiempo, deben tomar medidas para protegerse y legitimarse frente a los daños que esto origina (2012). Los gobiernos defienden así al modelo extractivista como condición esencial para financiar el fortalecimiento del Estado y luchar contra la pobreza a través de los excedentes. La apelación a las exportaciones y la globalización pasa entonces a estar revestida por las invocaciones del bienestar social y la atención a los más pobres, con lo cual el modelo logra una gran legitimidad política y social en amplios sectores tanto de las "derechas" productivistas como de las "izquierdas" oficialistas (Giarracca, 2012).

"Bajo estas condiciones deja de discutirse la esencia del estilo del desarrollo y su adaptación de un cierto tipo de inserción global y el debate parece derivar hacia el monto de las transferencias que se deben distribuir o el nivel de tributación a cobrar a los exportadores mineros, petroleros o sojeros" (Gudynas, 2012). Es por ello que las actuales luchas socio-ambientales actualizan un conjunto de debates nodales respecto de la concepción del desarrollo, de la visión de la naturaleza, del lugar del indígena en la construcción nacional y continental con una beligerancia y talante radical como quizás nunca antes se había dado (Svampa, 2012). 


\subsection{Metodología}

En este trabajo planteamos como objetivo describir algunos indicadores que nos permitan visibilizar la desigualdad socio-territorial en las áreas rurales del NOA en la primera década del siglo XXI. Para ello, el análisis se realizó sobre la población rural (agrupada y dispersa) de los 98 departamentos de las cinco provincias que integran la región del NOA (Jujuy, Salta, Tucumán, Santiago del Estero y Catamarca $)^{5}$ (figura 1), teniendo en cuenta cuatro dimensiones: 1) pobreza, 2) educación, 3) calidad del hábitat y 4) estructura agraria (tabla 1). Para observar los cambios en pobreza, educación y calidad del hábitat se utilizaron los censos nacionales de población 2001 y 2010, así como los datos de la Dirección de Estadísticas e Información en Salud para el período 2000-2012. Para el análisis de las transformaciones en la estructura agraria se observaron datos de los censos nacionales agropecuarios 1988, 2002 y 2008, y del sistema integrado de información agropecuaria, período 2005-2011.

TABLA 1

DIMENSIONES Y LAS VARIABLES ANALIZADAS

\begin{tabular}{l|l}
\hline DIMENSIONES & \\
\hline Pobreza & Mortalidad en la niñez por enfermedades de la pobreza (2000-2012) \\
\hline \multirow{4}{*}{ Educación } & Población rural mayor de diez años que no sabe leer ni escribir (2001-2010) \\
\cline { 2 - 2 } & Población rural mayor de diecisiete años que tiene secundario completo (2001-2010) \\
\cline { 2 - 2 } & Población rural mayor de veinticinco años que tiene universitario completo (2001-2010) \\
\hline \multirow{4}{*}{ Calidad del Hábitat } & Régimen de tenencia de la vivienda (2001-2010) \\
\cline { 2 - 2 } & Hacinamiento (2001-2010) \\
\cline { 2 - 2 } & Procedencia del agua para beber y cocinar (2001-2010) \\
\cline { 2 - 2 } & Tipo de vivienda particular (2001-2010) \\
\hline \multirow{5}{*}{ Estructura agraria } & Cantidad de Explotaciones Agropecuarias (EAPs) (1988-2002-2008) \\
\cline { 2 - 2 } & EAPs con y sin límites definidos (1988-2002-2008) \\
\cline { 2 - 2 } & Tamaño medio de las EAPs (1988-2002-2008) \\
\cline { 2 - 3 } & EAPs de menos de 25 has. y EAPs mayores de 2500 has. (1998-2002-2008) \\
\cline { 2 - 2 } & Exportaciones por provincia (2005-2011) \\
\hline
\end{tabular}

5 Se consideran todos los departamentos de las cinco provincias, excepto el departamento Capital de la provincia de Tucumán que no tiene población rural.

Estudios Geográficos, Vol. LXXVIII, 283, pp. 605-632, julio-diciembre 2017

ISSN: 0014-1496, eISSN: 1988-8546, doi: 10.3989/estgeogr.201721 


\section{FIGURA 1}

NOROESTE ARGENTINO. PORCENTAJE DE POBLACIÓN RURAL POR DEPARTAMENTO

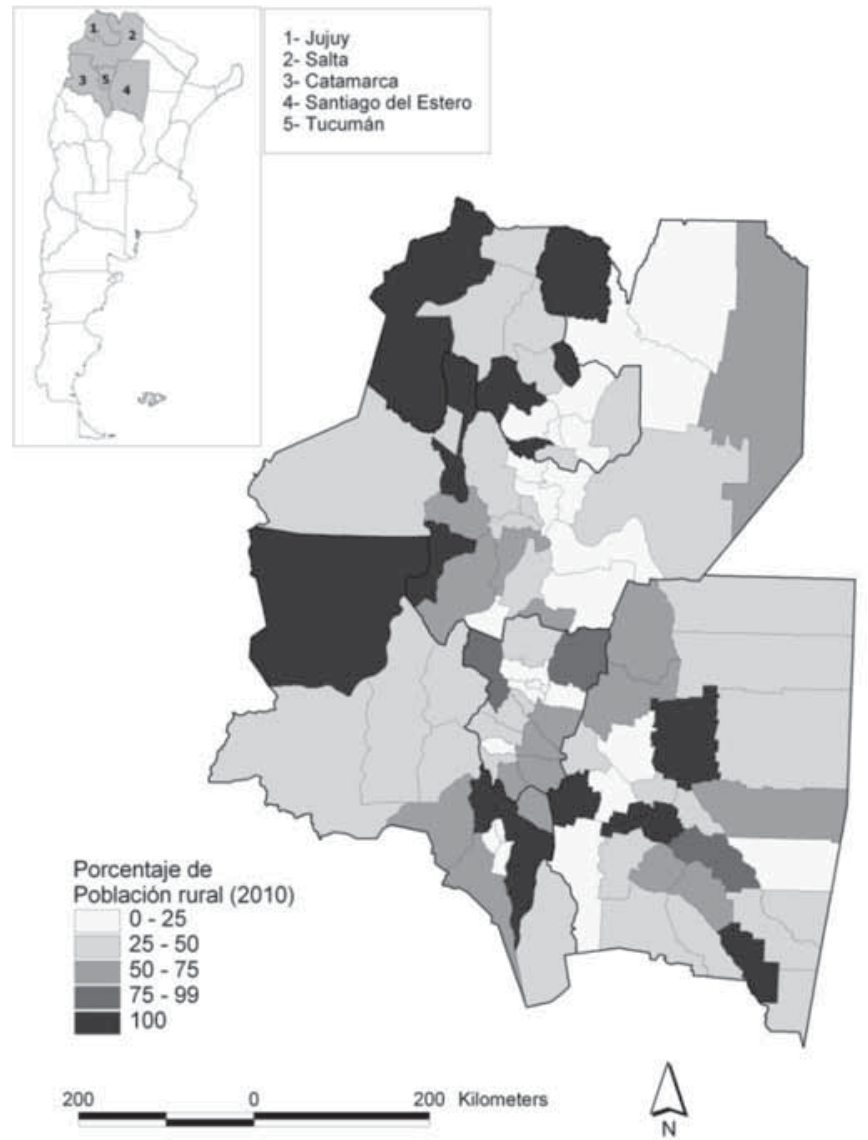

Fuente: Instituto Nacional de Estadísticas y Censos (2010).

\subsubsection{Conceptualizaciones y decisiones metodológicas}

Es preciso en este punto explayarnos en la argumentación de las decisiones metodológicas tomadas, señalando las limitaciones de las fuentes e indicadores que se utilizan. En primer lugar, debemos aclarar que en la actualidad, en Argentina, los métodos ortodoxos y las fuentes de datos para medir la pobreza se encuentran fuertemente cuestionados, y a esto se suma la dificultad para 
establecer criterios adecuados que permitan analizar este fenómeno en el medio rural, evitando los sesgos urbanos que implica el uso de indicadores como, por ejemplo, las Necesidades Básicas Insatisfechas. En este trabajo se analiza el indicador de la Mortalidad Infantil por Enfermedades de la Pobreza (MONEP) (Longhi, 2014) el cual, por la naturaleza de los datos utilizados para su construcción, tiene como máximo nivel de disgregación al departamento, por lo cual es imposible distinguir el componente rural de este indicador. A pesar de esta limitante, consideramos que el análisis de la distribución de la MONEP permite una excelente aproximación al fenómeno de la pobreza en la región y, para los casos de altos niveles de ruralidad en los departamentos, puede dar lugar a un buen conocimiento del fenómeno en el medio rural. El indicador se calculó utilizando datos de mortalidad en la niñez de la Dirección de Estadísticas e Información de Salud desde 2000 al 2012. La tasa se calcula cada mil habitantes ${ }^{6}$.

Respecto a la inclusión de la dimensión educación, existe un importante consenso en que, si bien las desigualdades sociales exceden a la dimensión educativa, también la incluyen (Steinberg et al., 2011) comprometiendo la posibilidad de mejorar las condiciones de vida. Tanto es así que, ya en 1961, las Naciones Unidas consideraron que era necesaria estudiarla para analizar el nivel de vida de la población (ONU, 1961). En Argentina, durante la primera década del siglo XXI, las políticas educativas han sido particularmente importantes, materializándose en la aprobación de legislación pertinente ${ }^{7}$. A la vez, con la implementación de la Asignación Universal por Hijo, se controla la asistencia escolar de los niños y niñas de las familias que acceden al beneficio. Actualmente, por otro lado, la obligatoriedad educativa abarca hasta el nivel secundario. Consideramos necesario, entonces, observar el comportamiento de tres variables: población rural mayor a diez años que no sabe leer ni escribir, población rural mayor a diecisiete años que tiene secundario completo y población mayor a veinticinco años que tiene universitario completo. Estos tres niveles nos permitirán observar el nivel de educación de la población rural y analizar los efectos de las políticas públicas.

Respecto a la dimensión calidad del hábitat, debemos aclarar que las variables escogidas son aquellas que se consideran valiosas para evaluar la situación concreta de los ámbitos rurales. Las categorías dentro de cada variable se clasificaron como críticas y no críticas. De este modo, en el caso

6 Para ver más detalladamente la estructura del indicador ver Longhi (2014).

7 Ley de educación (2006); Ley de Educación Técnico Profesional (2005); Ley de Financiamiento Educativo (2005); Ley de Garantía del Salario Docente y 180 días de clase (2003); Ley del Fondo Nacional de Incentivo Docente (2004); Ley de Protección Integral de los Derechos de las Niñas, Niños y Adolescentes (2005) y Ley Nacional de Educación Sexual Integral (2006).

Estudios Geográficos, Vol. LXXVIII, 283, pp. 605-632, julio-diciembre 2017

ISSN: 0014-1496, eISSN: 1988-8546, doi: 10.3989/estgeogr.201721 
de la variable tenencia de la vivienda, la única categoría donde el sujeto no se encuentra en una situación de vulnerabilidad es cuando es propietario de la vivienda y el terreno. En consecuencia, aquellas categorías que definen el régimen de tenencia crítico de la vivienda son: propietario solo de la vivienda, inquilino, ocupante por préstamo, ocupante por trabajo y otra situación.

El hacinamiento, por su parte, se define en consonancia a los parámetros establecidos por el Instituto Nacional de Estadísticas y Censos (INDEC), es decir, a partir de la convivencia de tres o más personas por cuarto. Con respecto a la procedencia de agua para beber, consideramos que los indicadores críticos son aquellos que corresponden a pozo ${ }^{8}$, transporte por cisterna y agua de lluvia, río, canal, arroyo o acequia, definiendo como no críticas a red pública, perforación con bomba a motor y perforación con bomba manual.

Por otra parte, en la variable tipo de vivienda particular, las categorías que provee el censo son casa, rancho, casilla, departamento, pieza en inquilinato, pieza en pensión, local no construido para habitación, vivienda móvil y personas viviendo en la calle. En este trabajo consideramos como no críticas a las viviendas tipo casa, rancho, departamento, pieza en inquilinato y pieza en pensión. Respecto a la vivienda tipo rancho, en muchos estudios se considera como vivienda precaria por su vinculación a la enfermedad de Chagas, generada por la picadura de la vinchuca, que se aloja en los techos de paja y en las grietas del adobe. Sin embargo, en este trabajo consideramos que el rancho en sí mismo no refleja a priori malas condiciones de vida para el hogar rural. El rancho es parte de la identidad de los pueblos del Noroeste Argentino y rescatamos su valor cultural. A su vez, un mejoramiento de las condiciones de vida y en los medios económicos del hogar rara vez impacta en la elección del tipo de vivienda rural, la cual, sostenemos, depende más de factores culturales y simbólicos que de factores económicos 9 .

Finalmente, respecto al uso de los datos del censo nacional agropecuario 2008, si bien inicialmente se consideró no utilizarlos debido a que el relevamiento no fue completado en algunas provincias y además se realizó durante el conflicto agrario de 2008, finalmente se decidió explorarlos y analizarlos de todas formas, evaluando críticamente el comportamiento de los datos y considerando

8 «Pozo: el hogar se abastece de agua por un sistema de captación que consiste en la extracción del agua de las napas superficiales a través de un medio mecánico de elevación (que puede ser manual o a motor) o bien a través de un balde o similar (sin utilizar medios mecánicos de elevación)» (INDEC, 2010).

9 Números análisis dan cuenta de la dificultad de tomar los indicadores de pobreza confeccionados para centros urbanos, específicamente por los criterios relacionados a la vivienda (ver por ejemplo: Murmis, 2001; Neiman et al, 2004; Forni, 2002). 
su evolución histórica. Por la misma razón es que en el análisis de la estructura agraria se toma un recorte temporal de 20 años (1988-2008), utilizando así los últimos tres censos nacionales agropecuarios (y no sólo los últimos dos) consiguiendo un mayor control sobre la evolución de los datos y así poder evaluar la consistencia de los resultados del análisis de los datos del censo 2008.

\section{Resultados}

Iniciar la descripción de los indicadores de la desigualdad socio-territorial obliga a realizar, a priori, un análisis de la evolución de la población rural durante la década. Al respecto, Bolsi señalaba la íntima relación entre las formas de uso y reparto de la tierra y la distribución de la población, destacando la importancia del análisis de esta última variable para visualizar, por un lado, el papel del medio natural y de los procesos históricos y, por el otro, el rol de los nuevos condicionamientos sociales, culturales, políticos y económicos (Bolsi, 1997).

De esta manera, los datos relevados durante la primera década del siglo XXI por el INDEC indican que la población rural del NOA disminuyó en términos absolutos y relativos. A principios de la década del 2000, la población rural superaba las 900 mil personas, representando un 21,7\% de la población total, mientras que a finales del período se observa una reducción en el orden de las 20 mil personas, pasando a significar, en términos relativos, un 19\% de la población total del NOA (Tabla 2). ${ }^{10}$ Tal reducción se concentró en la categoría de la población

TABLA 2

POBLACIÓN RURAL POR PROVINCIAS (2001-2010)

\begin{tabular}{l|c|c|c|c|c|c|c|c}
\hline \multirow{2}{*}{ Catamarca } & \multicolumn{2}{|c|}{ Rural Agrupado } & \multicolumn{2}{c|}{ Rural Disperso } & \multicolumn{4}{c}{ Población rural } \\
\cline { 2 - 9 } & 2001 & 2010 & 2001 & 2010 & 2001 & $\%$ & 2010 & $\%$ \\
\cline { 2 - 10 } & 59.844 & 59.637 & 26.985 & 24.485 & 86.829 & 26 & 84.122 & 22,9 \\
\hline Jujuy & 36.985 & 42.581 & 54.830 & 45.166 & 91.815 & 15 & 87.747 & 13 \\
\hline Salta & 61.400 & 60.433 & 117.480 & 97.386 & 178.880 & 16,6 & 157.819 & 13 \\
\hline Santiago del Estero & 65.584 & 71.589 & 207.268 & 201.988 & 272.852 & 33,9 & 273.577 & 31,3 \\
\hline Tucumán & 43.633 & 43.657 & 231.256 & 238.074 & 274.889 & 20,5 & 281.731 & 19,5 \\
\hline NOA & 267.446 & 277.897 & 637.819 & 607.099 & 905.265 & 21,7 & 884.996 & 19 \\
\hline
\end{tabular}

Fuente: Censos Nacionales de Población (2001-2010).

10 Valores muy altos si comparamos con el promedio nacional, donde el porcentaje de población rural no supera el $8 \%$.

Estudios Geográficos, Vol. LXXVIII, 283, pp. 605-632, julio-diciembre 2017

ISSN: 0014-1496, eISSN: 1988-8546, doi: 10.3989/estgeogr.201721 
rural dispersa. En efecto, la población rural agrupada se incrementó entre los dos últimos censos nacionales en el NOA. Sin embargo, todavía la mayor parte de la población rural sigue respondiendo a un hábitat disperso. Si comparamos, por otro lado, la población rural dispersa y concentrada por provincias, observamos que Catamarca y Salta presentan una disminución en ambas categorías. En cambio, Jujuy y Santiago del Estero presentan disminuciones en la población rural dispersa pero aumentos en la agrupada. Finalmente, Tucumán presenta leves aumentos en ambas categorías (Tabla 2).

\subsection{Pobreza}

Para analizar la evolución de la dimensión pobreza utilizamos el indicador de la Mortalidad de la niñez por enfermedades de la pobreza (Monep) el cual rescata el grado de capacidad de un grupo social para garantizar la vida y un entorno saludable de los niños, y evita la carga subjetiva en la definición de variables y umbrales de insatisfacción (Krapovickas y Longhi, 2013). El análisis de la evolución de este indicador nos permite afirmar que, para la región del NOA, entre 2000 y 2012 la pobreza y las condiciones de vida mejoraron levemente (figura 2). Partiendo de una tasa de 0.6 por mil, el indicador avanza hacia 2002 y 2003 hasta alcanzar valores promedios máximos de 0.8 por mil. A partir de allí comienza un descenso muy marcado mostrando valores muy bajos hacia el año 2005, pero volviendo a empeorar en los años siguientes. Sin embargo, es el último año analizado (2012) el que presenta el menor valor de la década (0.4 por mil).

FIGURA 2

MORTALIDAD EN LA NIÑEZ POR ENFERMEDADES DE LA POBREZA (MONEP) POR PROVINCIAS (2000-2012)
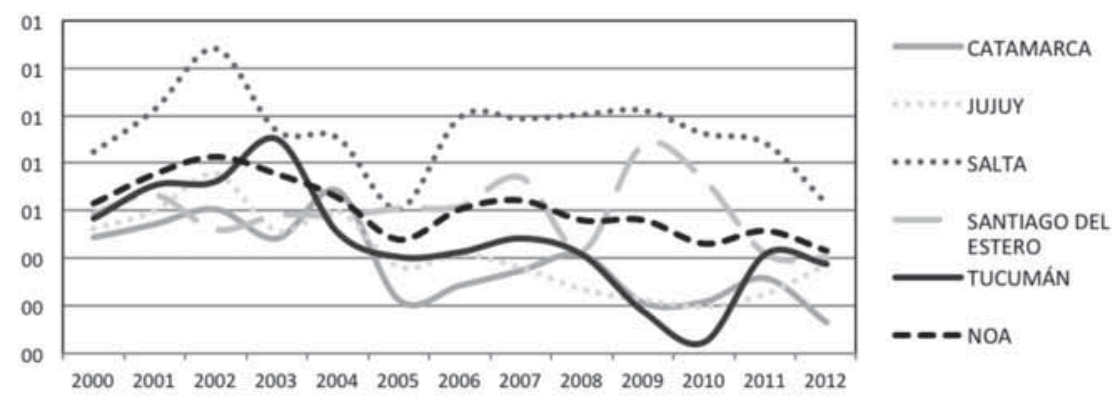

Fuente: Dirección de Estadísticas e Información en Salud (2000-2012) y Censos Nacionales de Población (2001-2010). 
Ahora bien, si analizamos las variaciones de la Monep a nivel provincial, rescatamos importantes diferencias. En primer lugar observamos que la provincia de Catamarca ha sido desde el comienzo de la década la que mejor desempeño tuvo, presentando las tasas más bajas tanto al comienzo como al final del período. Es interesante notar también que (exceptuando Salta, que presenta las tasas más altas durante toda la década, muy alejada del promedio regional) todas las provincias comienzan la década con valores altos y muy parejos ( 0.5 o 0.6 por mil), y durante la década presentan trayectorias muy diversas, culminando nuevamente en una convergencia hacia el valor promedio del NOA (0.4). Esa convergencia representa el final de una evolución dispar, donde Tucumán muestra una tendencia a la baja (luego de un pico en 2011), Santiago del Estero muestra estabilidad (tras registrar valores máximos de Monep en 2009), y Jujuy presenta un incremento de sus tasas (alejándose de su tasa mínima registrada en 2010).

\section{FIGURA 3}

EVOLUCIÓN DE LA MONEP POR DEPARTAMENTOS (2000-2012)

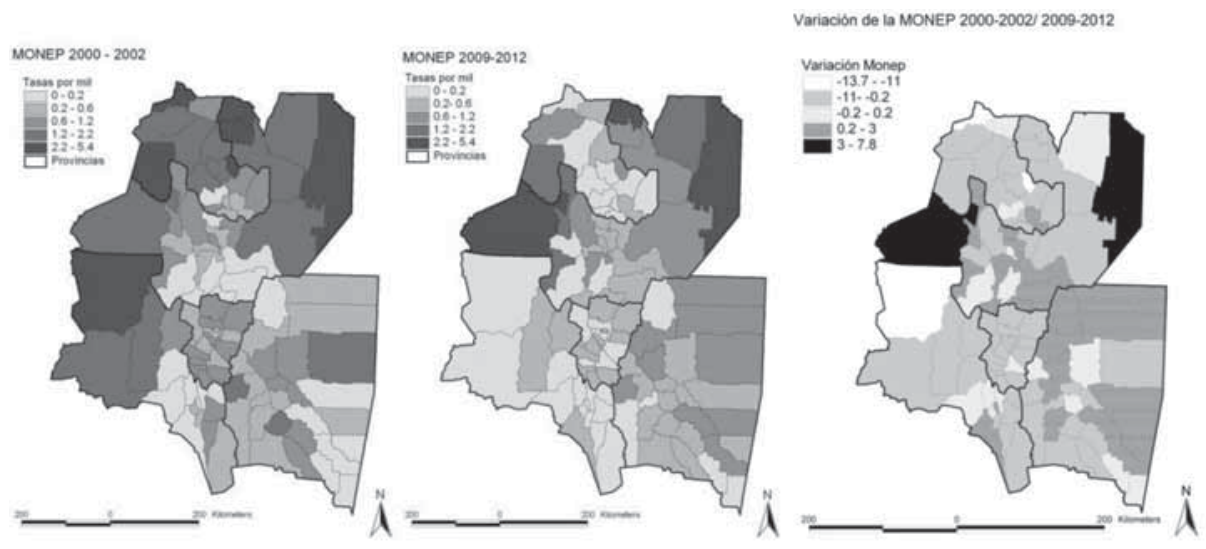

Fuente: Dirección de Estadísticas e Información en Salud (2000-2012) y Censos Nacionales de Población (2001-2010). Para la realización de este mapa se utilizaron los promedios de los datos de mortalidad de los trienios 2000-2002 y 2009-2012 para evitar que la alta variabilidad interanual del dato afecte la interpretación de los resultados.

La distribución y el comportamiento de la Monep a nivel departamental nos ofrece nuevamente una imagen de la diversidad de situaciones al interior de la región (figura 3). A pesar de las diferencias, algunas tendencias comunes pueden rescatarse. En primer lugar se destaca la distribución de las tasas más elevadas 
de Monep en el trienio que va desde 2000 al 2002 en las regiones andinas del NOA (es decir, hacia el oeste de la región) y del este de la provincia de Salta. En esos años se observan altas tasas de Monep en toda la provincia de Tucumán que, sin registrar los valores más altos del NOA, resalta por la homogeneidad de sus altos valores en todos los departamentos. Hacia el cuatrienio 20092012 la situación ha cambiado radicalmente en la región, observándose focos localizados de altas tasas de Monep en departamentos concretos y no en amplias regiones como en el período 2000-2002. Los departamentos más pobres se localizan exclusivamente en la provincia de Salta ${ }^{11}$, mientras las provincias de Catamarca, y Tucumán destacan por sus bajas tasas en todos los departamentos. La variación de la Monep por departamento nos permite observar, a su vez, que los departamentos que registraron importantes incrementos de sus tasas se localizan en las provincias de Salta y Santiago del Estero ${ }^{12}$, precisamente en las mismas zonas donde ya en el trienio 2000-2002 se registraban altas tasas. Es decir, en esos casos se manifiesta, no ya la persistencia de una situación de alta pobreza, sino incluso un empeoramiento de la situción crítica.

Si consideramos ahora los departamentos de altas proporciones de población rural del NOA, debemos destacar que, en la mayor parte de estos casos, las tasas de Monep sufren reducciones. Los departamentos con más del 50\% de la población residiendo en areas rurales en el NOA suman 40 casos. Dentro de este grupo encontramos 9 casos donde la Monep se incrementa, 5 donde la tasa permanece invariable y 26 casos donde la tasa se reduce. Por otro lado, en los departamentos netamente rurales del $\mathrm{NOA}^{13}$, vemos que disminuyen sus tasas de Monep con excepción de los departamentos La Poma y Molinos de Salta, donde se incrementa.

\subsection{Educación}

En la dimensión educación analizamos tres variables. La primera de éstas es el analfabetismo de la población rural mayor de 10 años de edad. Tal análisis nos permitió observar la existencia de mejoras consistentes en términos

11 Se trata de Rivadavia, Los Andes y Santa Victoria.

12 De los 98 casos analizados, en 25 se registró un incremento de la Monep: 2 casos en Catamarca, 1 en Jujuy, 11 en Salta y 11 en Santiago del Estero. En ningún departamento de Tucumán se registró un incremento de la Monep.

13 Los departamentos con 100 por ciento de población rural al 2010 son: Ambato, Ancasti, Antofagasta de la Sierra, El Alto y Paclin de Catamarca; Rinconada, San Antonio, Santa Catalina, Susques, Tumbaya y Valle Grande de Jujuy; Iruya, La Poma, Molinos, Santa Victoria de Salta; Figueroa, Guasayán, Mitre, San Martín y Silípica de Santiago del Estero. 
absolutos y relativos (tabla 3). Así pues, a principios de la década, la población rural analfabeta mayor de 10 años representaba el $6,9 \%$ de la población rural total (unas 62.333 personas) y hacia 2010, esos valores habían disminuido a $4,5 \%$, es decir 39.809 personas $^{14}$.

\section{TABLA 3}

DIMENSIÓN EDUCACIÓN

\begin{tabular}{l|c|c|c|c|c|c|c|c}
\hline \multirow{2}{*}{ PROVINCIAS } & \multicolumn{3}{|c|}{$\begin{array}{c}\text { Analfabetismo } \\
\text { (población mayor a 10 años de edad) }\end{array}$} & \multicolumn{3}{c}{$\begin{array}{c}\text { Secundario completo } \\
\text { (población mayor a 17 años) }\end{array}$} \\
\cline { 2 - 10 } & \multicolumn{2}{|c|}{2001} & \multicolumn{2}{c|}{2010} & \multicolumn{2}{c}{2001} & \multicolumn{2}{c}{2010} \\
\cline { 2 - 10 } & abs. & $\%$ & abs. & $\%$ & abs. & $\%$ & abs. & $\%$ \\
\hline Catamarca & 3.623 & 4,2 & 2.419 & 2,9 & 4.135 & 7,71 & 6.073 & 12,18 \\
\hline Jujuy & 6.765 & 7,4 & 4.097 & 4,7 & 3.310 & 6,22 & 5.294 & 10,64 \\
\hline Salta & 15.337 & 8,6 & 9.684 & 6,1 & 5.479 & 5,42 & 7.944 & 9,57 \\
\hline Santiago del Estero & 21.275 & 7,8 & 13.755 & 5,0 & 4.840 & 3,02 & 7.536 & 5,12 \\
\hline Tucumán & 15.333 & 5,6 & 9.854 & 3,5 & 9.263 & 5,46 & 14.763 & 9,11 \\
\hline NOA & 62.333 & 6,9 & 39.809 & 4,5 & 27.027 & 5,02 & 41.610 & 8,46 \\
\hline
\end{tabular}

Fuente: Censos Nacionales de Población (2001-2010).

A nivel provincial Jujuy muestra el mayor avance del NOA disminuyendo significativamente sus niveles de analfabetismo rural (pasando de 7,4 a 4,7\%) entre 2001 y 2010. La secunda Salta (que pasa de $8,6 \%$ a $6,1 \%$ ) y le siguen próximos Tucumán y Santiago del Estero. En términos relativos y absolutos Catamarca es la provincia que menos avanza, pero es también la provincia que partía (y finaliza) el período con los niveles más bajos de analfabetismo rural del NOA (pasando de presentar 4,2\% de su población rural analfabeta en 2001 a sólo 2,9\% en 2010). En contraposición, la provincia con mayor cantidad de población rural analfabeta en valores relativos es Salta, con 6,1\% en 2010.

Por otro lado, consideramos la evolución de la población mayor a diecisiete años con el secundario completo. A nivel regional observamos un aumento en términos absolutos y relativos. Iniciando la década, en 2001, correspondían al 5,02\% de la población adulta, equivalente a 27.027 personas. En 2010, representaban el 8,46\% (es decir, 41.610 personas) ${ }^{15}$. A nivel provincial, Cata-

14 La tasa de variación en el período es de -36\% (22.524 personas menos analfabetas en el medio rural).

15 La tasa de variación del período estudiado es de 54\% (14.583 jóvenes más que terminaron el secundario en el medio rural).

Estudios Geográficos, Vol. LXXVIII, 283, pp. 605-632, julio-diciembre 2017

ISSN: 0014-1496, eISSN: 1988-8546, doi: 10.3989/estgeogr.201721 
marca es la que muestra mayores avances con respecto a las demás provincias de la región (pasando de 7,71 a $12,18 \%$ ). Le siguen con valores próximos Jujuy (aumenta de 6,22 a 10,64\%) y Salta (de 5,42 a 9,57\%). Finalmente, están las provincias de Tucumán (de 5,46 a 9,11\%) y Santiago del Estero (de 3,02 a $5,12 \%$ ). Podemos observar que Santiago del Estero es la provincia con menor cantidad de población rural con el secundario finalizado en términos relativos.

Finalmente, analizamos la población mayor a veinticinco años que tiene el nivel universitario completo, ya que consideramos que a mayor nivel de instrucción existen más posibilidades de aportar a su comunidad. Así pues, podemos observar que los datos denotan un leve aumento en términos absolutos y relativos. A nivel regional, se puede observar un ascenso, de 0,58 a $0,83 \%{ }^{16}$.

Dentro de este panorama, a nivel provincial, tenemos comportamientos bastante heterogéneos. El primer grupo está compuesto por Tucumán y Jujuy, que muestran mejoras en términos absolutos y relativos, pasando de 0,47 a $1,08 \%$ ( 777 personas) y de 0,69 a $1,21 \%$ (219 personas) respectivamente. El otro grupo, compuesto por Santiago del Estero y Catamarca, presentan leves mejoras con porcentajes ínfimos, el primero de 0,18 a 0,25\% y el segundo 1,02 a 1,05\%. Por último, la provincia de Salta, si bien es la provincia que inicia la década con mayor porcentaje de población rural universitaria, demuestra a finales del periodo un descenso, pasando de 1,1 a $1,03 \%$.

\subsection{Calidad del Hábitat}

Como explicamos en la metodología, en esta dimensión se analizan las siguientes variables: régimen de tenencia de la vivienda, hacinamiento, procedencia de agua para beber (tabla 4) y tipo de vivienda. En el caso de la tenencia de la vivienda encontramos que, a nivel regional, la categoría propietario de vivienda y terreno ${ }^{17}$ ha aumentado del 56,5 a $65,2 \%$. A nivel provincial, observamos que Catamarca muestra los mayores porcentajes (valores superiores al $70 \%$ ), seguida de Santiago del Estero y Tucumán. Por otro lado, Jujuy y Salta presentan los valores más bajos apenas superando el $50 \%$ de los casos en 2010 en la primera y sin llegar a este valor en la segunda.

16 Esto representa una tasa de variación del 56\% (1.079 personas).

17 Para la variable tenencia de la vivienda, la única categoría que consideramos que no representa condiciones de vulnerabilidad es la de propietario de vivienda y terreno. 
Con respecto a las demás categorías que se consideran críticas, los datos muestran para el NOA una disminución en las categorías propietario solo de la vivienda (de $15,9$ a $11,4 \%)$, ocupante por préstamo $(10,9$ a $8,6 \%)$ y por trabajo $(11,6$ a 9,0). A su vez se registra un aumento en los regímenes de inquilinato ( 1,8 a 2,3\%) y en otra situación (3,2 a 3,5\%), aunque significan valores muy poco significativos. A finales de la década analizada existen $\mathbf{7 5 . 8 9 5}$ personas en situaciones habitacionales críticas, representando al 34,75\% de la población rural del NOA.

\section{TABLA 4}

\section{DIMENSIÓN CALIDAD DEL HÁBITAT}

\begin{tabular}{|c|c|c|c|c|c|c|c|c|c|c|}
\hline \multirow{3}{*}{ Provincias } & \multicolumn{4}{|c|}{ Régimen de tenencia de la vivienda } & \multirow{2}{*}{\multicolumn{2}{|c|}{ Hacinamiento }} & \multicolumn{4}{|c|}{ Procedencia de agua para beber } \\
\hline & \multicolumn{2}{|c|}{$\begin{array}{c}\text { Propietario } \\
\text { de la vivienda y } \\
\text { del terreno }\end{array}$} & \multicolumn{2}{|c|}{ categorías críticas } & & & \multicolumn{2}{|c|}{$\begin{array}{l}\text { categorías } \\
\text { no críticas }\end{array}$} & \multicolumn{2}{|c|}{ categorías críticas } \\
\hline & 2001 & 2010 & 2001 & 2010 & 2001 & 2010 & 2001 & 2010 & 2001 & 2010 \\
\hline Catamarca & 74,7 & 78,9 & 25,3 & 21,1 & 8,6 & 6,2 & 75,6 & 84,1 & 24,4 & 15,9 \\
\hline Jujuy & 44,5 & 50,4 & 55,5 & 49,5 & 15,7 & 9,8 & 59,4 & 71,5 & 40,6 & 28,5 \\
\hline Salta & 38,6 & 48,8 & 61,4 & 51,2 & 18,3 & 14,3 & 54,2 & 64,3 & 45,8 & 35,7 \\
\hline Santiago & 63,7 & 72,6 & 36,3 & 27,3 & 14,7 & 11,6 & 27,3 & 45,2 & 72,7 & 54,8 \\
\hline Tucumán & 59,8 & 68,5 & 40,1 & 31,6 & 13,8 & 9,4 & 71,5 & 84,3 & 28,5 & 15,7 \\
\hline $\mathrm{NOA}$ & 56,5 & 65,2 & 43,5 & 34,8 & 14,7 & 10,7 & 54,2 & 67,6 & 45,8 & 32,4 \\
\hline
\end{tabular}

Fuente: Censos Nacionales de Población (2001-2010).

En relación al hacinamiento en los hogares rurales, podemos observar que los valores han descendido durante la primera década del siglo XXI en el NOA (tabla 4). Observamos que en el año 2001 existían 29.350 hogares hacinados $(14,7 \%)$ y en el 2010 esta cifra baja a 23.275 (10,7\%), representando a aproximadamente 6.000 hogares menos (-20\%). En este caso, también los datos provinciales responden a la descripción regional, observándose disminuciones en todas las provincias, tanto en términos absolutos como relativos. La provincia donde más disminuye es Jujuy y donde menos lo hace es en Santiago del Estero ${ }^{18}$. En términos absolutos y relativos, Catamarca es donde menos población rural hacinada encontramos al final del período (apenas más de 1000 hogares, representando un 6,2\% de los hogares rurales). Por su parte,

18 Jujuy presenta una tasa de variación de su hacinamiento del orden del -33\% y Santiago del Estero - $12 \%$. 
Santiago del Estero es la provincia con mayor cantidad absoluta de hogares rurales hacinados, pero es Salta la que presenta el porcentaje más alto (14\%).

Con respecto a la procedencia de agua para beber, consideramos que los indicadores críticos son: agua de pozo, transporte por cisterna y agua de lluvia, río, canal, arroyo o acequia. A nivel regional, las categorías que muestran un aumento en el período son: red pública, perforación con bomba a motor y transporte por cisterna. En efecto, las demás categorías presentan una disminución, pequeña para el caso de la perforación con bomba manual pero bastante importante en las categorías pozo y agua de lluvia. Los datos nos demuestran que las condiciones han mejorado, ya que a inicios del siglo, el $45,8 \%$ de los hogares rurales del NOA se encontraba en situaciones críticas respecto del agua para beber y estos valores han descendido al 32,4\% (70.790 hogares) a finales de la década. El análisis a nivel provincial nos permite observar que Catamarca presenta la mayor cobertura de red pública de suministro de agua en el área rural del NOA ( $70 \%$ de hogares en 2001 y $77 \%$ en 2010). La secundan Jujuy y Tucumán, las cuales superaban el 60\% de cobertura en 2010. Salta, por su parte, no supera el $50 \%$ al final del período analizado y, lejos de esta cobertura, en Santiago del Estero apenas abarcaba al 35\% de los hogares.

Finalmente, analizamos el tipo de vivienda particular, donde observamos que en las categorías no críticas las casas presentan un aumento del 68,4 al $77,4 \%$. Por su parte, el rancho pasó de 26 a $18 \%$ y los departamentos, piezas en inquilinato y piezas en pensión permanecen prácticamente invariables con valores insignificantes. Con respecto a las categorías críticas, podemos observar que las casillas aumentaron levemente (3,7 a 3,9\%): los locales no construidos para habitación disminuyeron $(0,2$ a $0,1 \%)$, la vivienda móvil se mantuvo en $0,2 \%$ y las personas viviendo en la calle prácticamente desaparecieron, pasando de 0,1 a $0 \%$.

\subsection{Transformaciones territoriales y en la estructura agraria}

El Noroeste Argentino podría ser caracterizado por los marcados contrastes en su paisaje natural. De esta manera, las áreas montañosas y los desiertos ocupan una proporción destacada en la superficie regional. Sin embargo, esa variedad de paisajes no se refleja en una gran diversidad económico-productiva ya que la economía regional sigue estando conducida por las producciones primarias, las cuales se apoyan en una estructura agraria históricamente desequilibrada (Bolsi, 1997) ${ }^{19}$. En esta sección nos centraremos precisamente

19 Bolsi señala que, si bien es cierto que esa estructura agraria acusa el peso de la herencia colonial, debe destacarse también que fueron poco eficaces los esfuerzos posteriores para 
en el análisis de la estructura agraria, haciendo hincapié en la evolución del uso y reparto de la tierra en el NOA entre 1988 y 2008 y la composición de las exportaciones por región y por provincia.

Considerando entonces, en primer lugar, el total de las explotaciones agropecuarias (EAPs) en las dos décadas analizadas, observamos que en la región del NOA se constata una notable disminución en el número absoluto de las mismas. Mientras en 1988 el total de EAPs llegaba casi a 65 mil unidades, en 2008 apenas superaban las 50 mil (tabla 5). Las provincias que mayor reducción mostraron en el número de EAPs son Tucumán y Santiago del Estero, pasando de 16.500 a menos de la mitad (7.600) y de 21.000 a aproximadamente 16.000 respectivamente ${ }^{20}$. Catamarca, por su parte, mostró una reducción leve en la cantidad de EAPs. En contraposición, en Jujuy y Salta la cantidad de EAPs se incrementó en el período considerado. En el primer caso el incremento fue de apenas un 2,4\%, mientras en el segundo ascendió al 11,8\%. De este modo, tomando como punto de partida los valores de 1988, mientras en toda la región el total de EAPs se reduce en un 20\%, en Santiago del Estero se reducen en un $25 \%$ y en Tucumán la reducción es del orden del 54\%.

TABLA 5

DIMENSIÓN ESTRUCTURA AGRARIA

\begin{tabular}{l|r|r|r|r|r|r|r|r|r}
\hline \multirow{2}{*}{ Provincias } & \multicolumn{3}{|c|}{ EAPs Totales } & \multicolumn{3}{c|}{ Con límites definidos } & \multicolumn{3}{c}{ Sin límites definidos } \\
\cline { 2 - 11 } & 1988 & 2002 & 2008 & 1988 & 2002 & 2008 & 1988 & 2002 & 2008 \\
\hline Catamarca* & 9.538 & 9.138 & 9.012 & 6.988 & 6.694 & 6.959 & 2550 & 2444 & 2053 \\
\hline Jujuy* & 8.526 & 8.983 & 8.733 & 4.286 & 4.061 & 4.820 & 4240 & 4922 & 3913 \\
\hline Salta* & 9.229 & 10.297 & 10.317 & 4.798 & 5.575 & 6.808 & 4431 & 4722 & 3509 \\
\hline Santiago del Estero* & 21.122 & 20.949 & 15.899 & 11.532 & 10.830 & 11.033 & 9590 & 10119 & 4866 \\
\hline Tucumán** & 16.571 & 9.890 & 7.669 & 15.998 & 9.555 & 7.602 & 5730 & 3350 & 67 \\
\hline NOA & 64.986 & 59.257 & 51.630 & 43.602 & 36.715 & 37.222 & 26.541 & 25.557 & 14.408 \\
\hline
\end{tabular}

Nota: * Provincias con superficie censada en 2008 superior al 95\% de la del Censo Nacional Agropecuario 2002; ** Provincia con superficie censada en 2008 inferior al 95\% de la del CNA 2002. Fuente: Censos Nacionales Agropecuarios 1988, 2002 y 2008.

equilibrarla. Desde mediados del siglo XX el proceso prácticamente no varió, excepto por la lenta desaparición de las pequeñas explotaciones, relacionadas con la extinción del campesinado (Bolsi, 1997).

20 Es necesario recordar que para Tucumán los datos del censo 2008 no son del todo fiables ya que es la única provincia de la región donde la superficie censada fue inferior al $95 \%$ de la superficie censada en el 2002, según los propios datos del INDEC.

Estudios Geográficos, Vol. LXXVIII, 283, pp. 605-632, julio-diciembre 2017

ISSN: 0014-1496, eISSN: 1988-8546, doi: 10.3989/estgeogr.201721 
En relación a la evolución de la cantidad de EAPs con y sin límites definidos, vemos que la tendencia más fuerte fue la disminución de estas últimas, tanto a nivel regional como provincial. Entre 1988 y 2008 la región en su conjunto perdió unas 6000 EAPs con límites definidos (CLD), pero la reducción de las EAPs sin límites definidos (SLD) fue mucho más importante, implicando la desaparición de unas 12000 unidades. Otra diferencia en la evolución de ambas es que mientras las primeras (CLD) descendieron fuertemente sólo en la provincia de Tucumán, en el caso de las segundas (SLD), se redujo su cantidad en todas las provincias. En efecto, las EAPs con límites definidos aumentaron en Salta y Jujuy y prácticamente se mantuvieron invariables en Catamarca y Santiago del Estero. En cambio, las EAPs sin límites definidos (otrora muy importantes en la región, dada la importancia de los modos campesinos de producción) ${ }^{21}$ redujeron drásticamente su presencia en el período analizado en todas las provincias. ${ }^{22}$ Es importante notar que la reducción de la proporción de las explotaciones SLD sobre el total se concretiza durante los últimos 6 años analizados (2002-2008), lo que nos da una idea de la magnitud y rapidez de las transformaciones territoriales operadas en la región.

FIGURA 4

\section{EAPS SIN LÍMITES DEFINIDOS (2002-2008)}
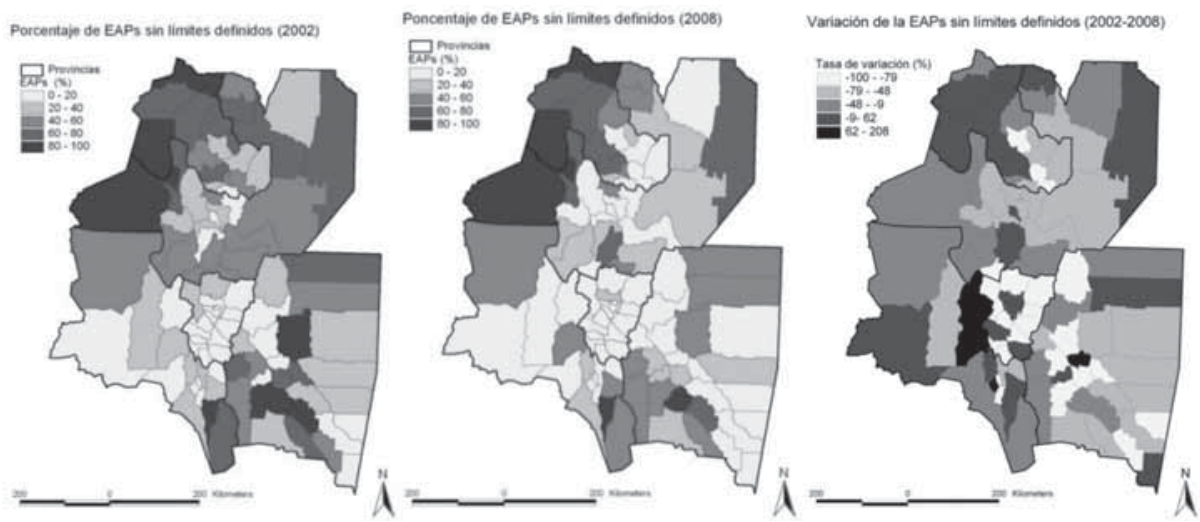

Fuente: Censos Nacionales Agropecuarios (2002 y 2008).

${ }^{21}$ Los regímenes de tierra relacionados a este tipo de explotación son los de ocupantes de tierras privadas y fiscales, campos comuneros, aparcerías precarias y sucesiones indivisas, donde el campesinado constituye el principal poblador (Paz y Jara, 2014).

22 Sin duda el dato de la provincia de Tucumán vuelve a llamar la atención, mostrando una virtual desaparición de las EAPs sin límites definidos para el último censo, lo cual hace nuevamente dudar de la calidad del dato. 
Ahora bien, si analizamos la distribución de las EAPs sin límites definidos a nivel departamental y su variación entre los dos últimos censos, observamos que la situación al interior de cada provincia puede ser muy variable. En 2002, tal como se observa en la figura 4, los departamentos con mayor proporción de este tipo de EAPs se encontraban en las provincias de Salta, Jujuy y Santiago del Estero, fundamentalmente en las regiones andinas y en la llanura chaqueña. Sin embargo, sólo 6 años después encontramos en todas las provincias, menos departamentos donde las EAPs sin límites definidos representen más del $60 \%$ de las unidades productivas. Los departamentos que siguen concentrando estas EAPs se agrupan ahora casi exclusivamente en la región andina de Salta y de Jujuy.

Por otro lado, con respecto al tamaño medio de las EAPs, observamos que durante las dos décadas analizadas, la tendencia fue hacia un leve incremento de la superficie media: el tamaño medio de las EAPs pasó de 270 hectáreas en 1988 a 326 has en 2008. La situación al interior de la región, sin embargo, presenta marcados contrastes, donde algunas provincias como Salta y Jujuy se separan de la tendencia general mostrando una fuerte reducción en las superficies medias de sus EAPs. Por su parte, Tucumán y Santiago del Estero presentan los incrementos más notables.

En relación a la distribución y variación en los extremos de la estructura agraria en la región, es decir, las variaciones en la cantidad de EAPs pequeñas (menos de 25 hectáreas) y EAPs grandes (más de 2500 hectáreas), observamos que hacia 2008 los departamentos con más alta proporción de minifundios se concentraron hacia el oeste de la región, en las zonas montañosas. La mayor parte de los departamentos de las provincias de Tucumán y Catamarca presentaron en el último censo proporciones muy altas de EAPs con menos de 25 hectáreas (en muchos casos el porcentaje supera el $80 \%$ de las unidades productivas). En contraposición, las EAPs de más de 2500 hectáreas se concentraban en 2008 hacia el este de la región del NOA, sobre la llanura chaqueña de Salta y Santiago del Estero ${ }^{23}$ (Fig. 5).

La variación entre 1988 y 2008 a nivel departamentos para ambos casos (minifundios y latifundios) presenta una amplia variedad de situaciones. En el caso de los minifundios, se destacan los casos de la provincia de Tucumán y Catamarca donde, en 2008, a pesar de mantener altas proporciones de EAPs pequeñas respecto del total, se evidencia una reducción muy marcada de este tipo de unidades productivas durante las dos décadas. Considerando ahora el

23 Se destacan los casos de los departamentos de Anta (Salta) y Moreno (Santiago del Estero).

Estudios Geográficos, Vol. LXXVIII, 283, pp. 605-632, julio-diciembre 2017

ISSN: 0014-1496, eISSN: 1988-8546, doi: 10.3989/estgeogr.201721 


\section{FIGURA 5}

DISTRIBUCIÓN DE EAPS PEQUEÑAS Y GRANDES EN 2008

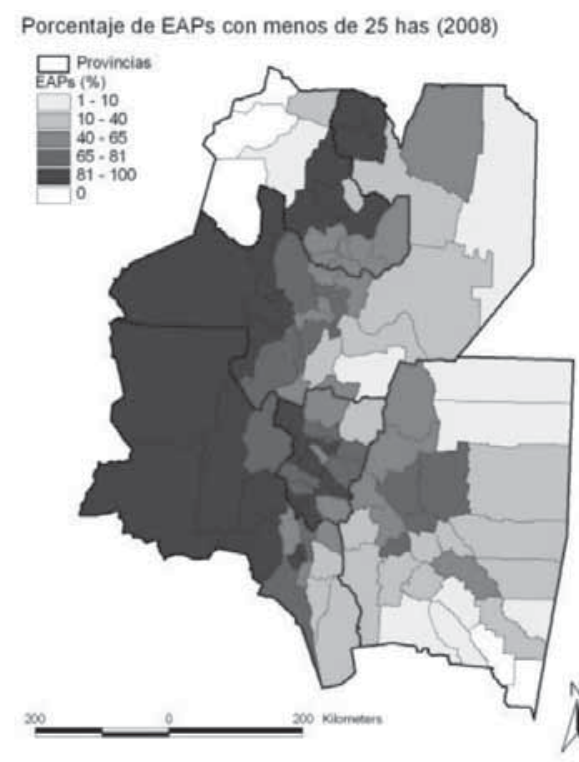

Porcentaje de EAPs con más de 2500 has (2008)

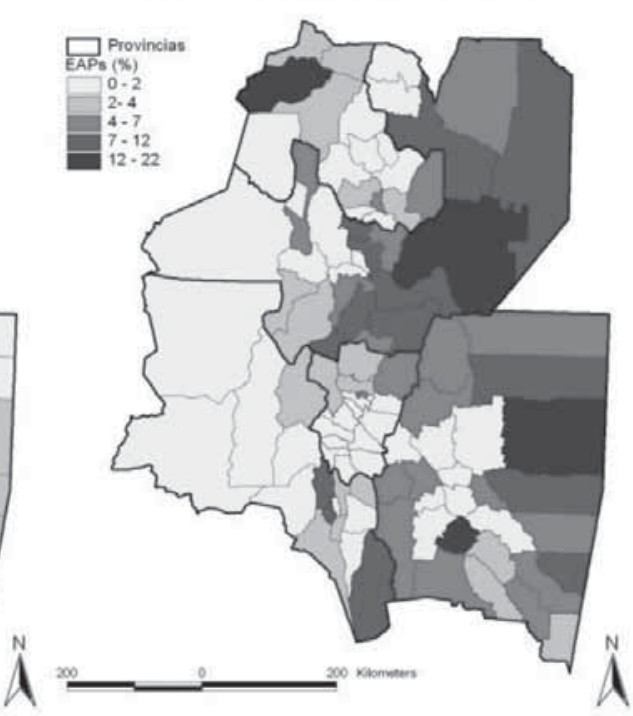

Fuente: Censos Nacionales Agropecuarios (1988 y 2008).

caso de la evolución de los latifundios, observamos que la situación es muy dispar al interior de las provincias, mostrando tendencias hacia la estabilidad y aumento de estas unidades en las principales zonas productivas de Catamarca y Santiago del Estero. En el caso de Salta se destacan los departamentos del este (Rosario de la Frontera, Metán, Anta, Orán y San Martín) — principal zona de expansión sojera - donde la tendencia entre 1988 y 2008 es la reducción o estabilidad en la cantidad de EAPs de más de 2500 hectáreas.

Finalmente, el último elemento a considerar en este análisis es la composición de las exportaciones a nivel regional y provincial. Como mencionamos antes, en la región históricamente fueron las actividades primarias las que motorizaron la economía y actualmente las áreas más dinámicas están representadas (además de los cereales y oleaginosas) por la minería (fundamentalmente de cobre, plata y oro), la citricultura, la caña de azúcar, la ganadería, la vitivinicultura, olivicultura y otras agroindustrias. El crecimiento de estas actividades explicarían el incremento de las exportaciones regionales operadas entre 2005 y 2011 (figura 6). Observamos entonces que si en 2005 casi el $60 \%$ de las exportaciones correspondían a 
productos primarios, en 2011 ese porcentaje se eleva hasta alcanzar el 74\% y es precisamente el incremento de las exportaciones primarias el que explica casi todo el incremento de las exportaciones totales, ya que las Manufacturas de Origen Agropecuario, las Manufacturas de Origen Industrial y los combustibles se mantienen aproximadamente invariables en el período analizado.

FIGURA 6

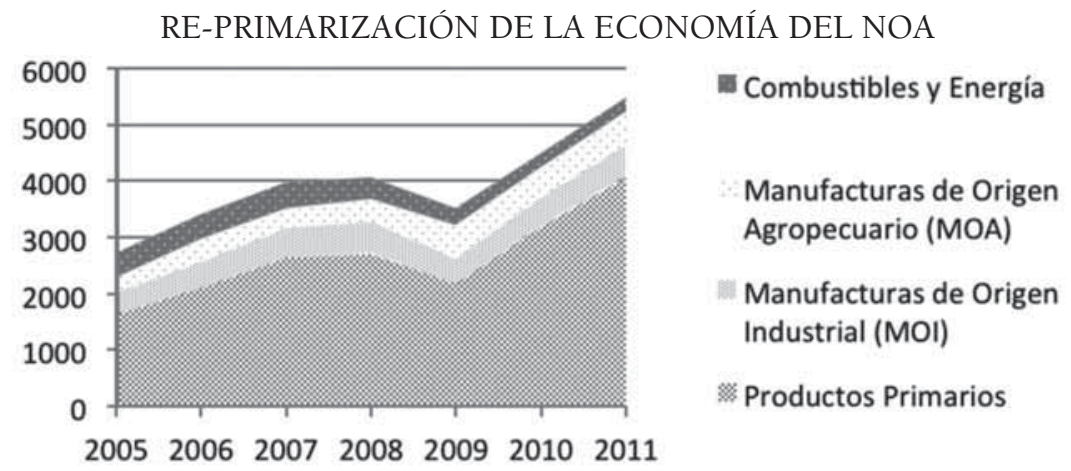

Nota: Evolución de las exportaciones de Combustibles y Energía (Comb) Productos Primarios (PP), Manufacturas de Origen Agropecuario (MOA) y Manufacturas de Origen Industrial (MOI). Millones de dólares. Período 2005-2011.

Fuente: sistema integrado de información agropecuaria.

Analizando este dato a nivel provincial, observamos el comportamiento diferencial al interior de la región. Así, si consideramos los ingresos por exportaciones de MOI, vemos que es Tucumán la provincia que al 2011 aportaba más de la mitad de los ingresos regionales en este ítem (casi 300 millones de dólares), muy por arriba de las demás provincias, significando también un porcentaje elevado de los ingresos por exportaciones a nivel provincial $(28,6 \%)$. Mientras tanto, en las demás provincias, los ingresos por exportaciones de MOI no superaban al 2011 el $7 \%$ de los ingresos provinciales. La situación se repite al considerar las MOA, donde todas las provincias excepto Tucumán (con un 31,7\%) presentan porcentajes menores al 10\%. Por el contrario, los ingresos por exportaciones de PP revelan gran importancia en la mayoría de las provincias, algunas de las cuales casi no exportan otros ítems, como Catamarca $(90,7 \%)$ y Santiago del Estero $(90,7 \%)$. A su vez, Salta es la única provincia que exporta combustibles. Siguiendo el análisis de estos datos, podemos afirmar que las economías más primarizadas son las de Catamarca, Salta y Santiago del Estero, mientras la más diversificada es la de Tucumán. 


\section{A MODO DE SÍNTESIS}

Para el análisis descriptivo de la desigualdad socio-territorial en los sectores rurales del NOA se analizaron (a nivel departamental, provincial y regional) 13 variables, agrupadas en 4 dimensiones. A pesar de la dificultad de resumir la complejidad de los patrones analizados, en parte por la presencia de tendencias contrapuestas a diferentes escalas, recopilamos las evoluciones más importantes en este apartado de síntesis, el cual se lleva a cabo a nivel provincial por considerarse el nivel más apropiado para el análisis de una región.

Recordemos que partimos de un contexto regional que cuenta aproximadamente con un $20 \%$ de población rural, la cual en su mayoría reside de modo disperso en el campo pero con una fuerte tendencia hacia la concentración en los pueblos cabecera $^{24}$. Una región que concentra la mayor parte de la población indígena del país y con un campesinado con tendencias históricas hacia su descomposición.

Para esta recapitulación elegimos 5 variables que sintetizan la esencia de cada una de las dimensiones antes analizadas con detalle. Estos son: la Monep, el analfabetismo, el hacinamiento, los minifundios y EAPs sin límites definidos y la composición de las exportaciones. La siguiente figura muestra una valoración cualitativa de la evolución de estas variables durante la primera década del siglo XXI (figura 7).

A partir de esta síntesis, podemos observar que las políticas públicas han sido eficientes a la hora de mejorar las condiciones habitacionales y educativas de la población del NOA. Sin embargo, estas mejoras no han repercutido en todos los casos en un descenso de los niveles de mortalidad infantil por enfermedades de la pobreza, lo cual se hace particularmente evidente en Jujuy, Salta y Santiago del Estero ${ }^{25}$. Sin duda, la razón de esta falta de correlación entre el éxito de unas políticas sociales y el fracaso en materia de reducción de la Monep puede encontrarse en múltiples factores, los cuales pueden diferir, dependiendo los casos, entre las provincias y el interior de las mismas. No obstante consideramos que, tratándose del medio rural, el factor productivo tierra puede explicar en gran medida esta falta de correlación. ¿Cuál ha sido la tendencia, durante estos años de fuerte intervención estatal en múltiples ramas de la economía, del factor productivo tierra en el NOA? Los resultados expuestos indican que la tierra ha tendido a una concentración.

24 La urbanización se acelera de la mano de la migración rur-urbana. Los pueblos crecen y pasan a ser a ser considerados por el INDEC como ciudades, una vez que cruzan la barrera de los 2000 habitantes.

25 Salta y Santiago registran la mayoría de los casos de aumentos de la monep. 
FIGURA 7

VALORACIÓN CUALITATIVA DE LA EVOLUCIÓN DE LAS PRINCIPALES VARIABLES ANALIZADAS

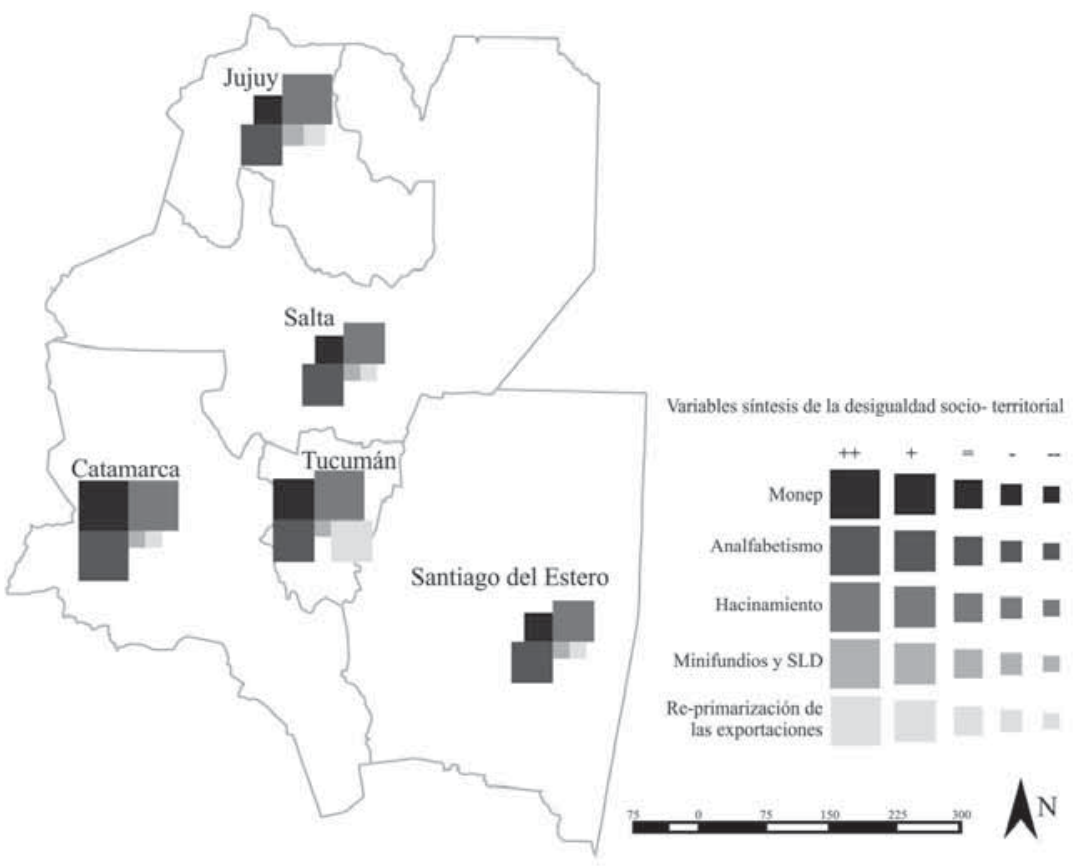

Las explotaciones minifundistas y las sin límites definidos, relacionadas a modos de producción campesino han disminuido notablemente en este período. ¿Podemos suponer que la desaparición de las EAPs SLD responde a una tendencia a la formalización de la tenencia de la tierra en la región? En algunos casos puede suceder que sí, sobre todo cuando vemos que el descenso en las EAPs SLD se corresponde con un aumento en las CLD (Jujuy y Salta por ejemplo). Sin embargo, las evidencias no sugieren que esta sea la tendencia general. Al observar la matriz productiva de las provincias y encontrar el enorme crecimiento de las exportaciones de productos primarios durante la década, confirmamos que la base estructural de la riqueza sigue concentrada $^{26}$. Los productos que exporta el NOA son principalmente fruto

26 Los campesinos y comunidades originarias del NOA no exportan sus producciones. Su producción generalmente no se comercializa ya que es de uso familiar, o se comercializa a nivel local. 
de la actividad mega-minera, de la vitivinicultura, y del monocultivo de oleaginosas. Todas actividades que son comandadas por grandes empresas; muchas veces extranjeras y sin casas matrices en la región.

Vistos entonces los magros resultados en la reducción de la pobreza, podemos decir que la estrategia extractivista fracasa. De las cinco provincias analizadas, sólo en Catamarca encontramos que la reducción de la pobreza se acompaña a la vez de una estructura de tenencia de la tierra desigual y una matriz productiva orientada al mercado externo y comandada por grandes empresas. Jujuy, Salta y Santiago del Estero, con tendencias similares en cuanto a estructura agraria, presentan resultados lamentables mientras Tucumán, con una economía más diversificada, logra quedar al menos a mitad de camino.

\section{Conclusiones}

Los datos analizados en este trabajo nos permiten afirmar la hipótesis de la persistencia de las desigualdades. La base para el crecimiento económico y el aumento de los ingresos de la región siguen siendo (como lo ha sido históricamente) la explotación y la exportación de recursos naturales, fortaleciendo el modelo económico neoliberal. Ante esto se señala que nos enfrentamos a un nuevo boom extractivista en la región. Teniendo presente entonces que bajo el desarrollo de esta geopolítica extractivista el papel del Estado es clave como garante del traspaso de fondos y ganancias extraordinarias hacia los sectores populares, es que podemos observar estas mejoras en ciertas variables e indicadores sociales. Sin embargo, en un contexto donde la estructura agraria es cada vez más desigual, la vulnerabilidad de estas poblaciones se sostiene - y en algunos casos se incrementa - persistiendo las desigualdades entre territorios y, fundamentalmente, entre grupos sociales destinados a ganar y a perder. Así pues, sostenemos que los principales afectados del extractivismo son los indígenas, campesinos y agricultores familiares, poniendo de manifiesto la «vulnerabilidad selectiva» a la que hacía referencia Harvey (2003). Los efectos sociales que implican la pérdida de la tierra y los medios de vida para estas poblaciones se manifiestan en la Monep, que aunque desciende a nivel general en la región y en las provincias, a nivel departamental se incrementa precisamente en los territorios sometidos a políticas extractivistas.

A pesar de la diversidad de situaciones a nivel departamental y provincial, la tendencia regional es más que contundente: la estructura agraria en el NOA manifiesta una gran desigualdad socio-territorial, fruto de una geo-política extractivista y de estructuras productivas desiguales de larga data, que impiden 
que toda política tendiente a distribuir ingresos o mejorar ciertos aspectos clave de la calidad de vida de la población, no lleguen a subsanar la desigualdad entre grupos sociales y entre territorios.

\section{Bibliografía}

Agis, E., Cañete, C. y Panigo, D. (2010): "El Impacto de la Asignación Universal por Hijo en Argentina". Documento de trabajo CEIL-PIETTE, Argentina. En línea: http:// www.trabajo.gov.ar/left/estadisticas/documentossubweb/areal/documentos/auh_ en_argentina.pdf (acceso: 05/05/2016)

Bauman, Z. (2008): La globalización, consecuencias humanas, Buenos Aires, FCE.

Bolsi, A. (1997): "La distribución de la población, 1869-1991", en Bolsi, A. (comp.), Problemas Poblacionales del Noroeste Argentino (contribuciones para su inventario), Tucumán, Universidad Nacional de Tucumán - Junta de Andalucía, pp. 35-46.

Bolsi, A. (2004): "La población del Noroeste argentino durante el siglo XX", Travesía 7/8, pp. 9-52.

Bolsi, A.; Paolasso, P. y Longhi, F. (2006): "El Norte Grande Argentino entre el progreso y la pobreza", Población y Sociedad núm. 12/13, pp. 227-266.

Forni, F. (2002): "Caracterización dinámica de situaciones de pobreza en la Argentina", en Murtagh, R. (coord.), Pobreza urbana en la Argentina. Desde un enfoque multidisciplinar hacia una praxis interdisciplinaria, Argentina: Departamento de Investigación Institucional. Instituto para la Integración del saber, Pontificia Universidad Católica Argentina, pp.22-42.

Gasparini, L. y Cruces, G. (2010): "Las asignaciones universales por hijo en Argentina: Impacto, discusión y alternativas", Económica, Vol. LVI (1): 105-146.

Giarracca, N. (2012): "Tres paradojas para repensar la política", en Massuh, G. (edit.), Renunciar al bien común: extractivismo y (pos) desarrollo en América Latina, Buenos Aires, Mardulce, pp. 191-235.

Giarracca, N. y Teubal, M. (2010): "Disputas por los territorios y recursos naturales: el modelo extractivo", Revista Alasru Nueva Época, núm. 5, pp. 113-133.

Göbel, B.; M. Góngora-Mera y A. Ulloa (2014): "Las interdependencias entre la valorización global de la naturaleza y las desigualdades sociales: abordajes multidisciplinarios", en: Göbel, B.; M. Góngora-Mera y A. Ulloa (ed.) (2014) Desigualdades socioambientales en America Latina. Bogotá, Universidad Nacional de Colombia, Berlín, Ibero-Amerikanisches Institut.

Gudynas, E. (2012): "La crisis global y el capitalismo benévolo de la nueva izquierda criolla", en Massuh, G. (edit.) Renunciar al bien común: extractivismo y (pos) desarrollo en América Latina, Buenos Aires, Mardulce, Pp. 103-127.

Harvey, D. (2003) Espacios de Esperanza. Madrid, Akal, 336 pp. 
Instituto Nacional de Estadísticas y Censos (INDEC) (2010): Definiciones de la Base de datos. En línea: http://200.51.91.245/argbin/RpWebEngine.exe/PortalAction?\&M ODE=MAIN\&BASE=CPV2010B\&MAIN=WebServerMain.inl (acceso 02/02/2016)

Kessler, G. (2014): Controversias sobre la desigualdad: Argentina, 2003-2013, Buenos Aires, FCE, 380 pp.

Krapovickas, J. y Longhi, F. (2013): "Pobrezas, ruralidades y campesinos en el Chaco Argentino a comienzos del siglo XXI", Estudios rurales, 1 (4), pp. 38-76.

Longhi, F. (2014): "Desnutrición y Muerte en la Niñez argentina en los Albores del Siglo XXI: Un Análisis Espacial”, Journal of Latin American Geography 13(2), pp. 41-65.

Longhi, F; Bolsi, A.; Velázquez, G.; Paolasso, P. y Celemín J. P. (2013): "Fragmentación socio-territorial y condiciones de vida en Argentina en los albores del siglo XXI", Revista Latinoamericana de Población, 7 (12), pp. 99-131.

Murmis, M. (2001): Pobreza rural (diversidad de situaciones ocupacionales), Buenos Aires, PROINDER, 53 pp.

Neiman, G.; Blanco, M. y Jiménez, D. (2004): "Desde abajo. La participación de las redes familiares y sociales en la subsistencia de los sectores rurales pobres", en Forni, F. (comp.), Caminos solidarios de la economía Argentina. Redes innovadoras para la integración, Buenos Aires, Ciccus, pp. 289-309.

Organización de las Naciones Unidas (ONU) (1961): Definición y medición internacional del nivel de vida. Guía provisional, Nueva York, Naciones Unidas, pp. 24.

Paolasso, P.; Longhi, F; Velázquez, G. y Celemín, J.P. (2014): "Persistencias y transformaciones territoriales en Argentina durante la primera década del siglo XXI", VI Congreso de la Asociación Latinoamericana de Población, realizado en LimaPerú, 12 al 15 de agosto de 2014.

Paolasso, P.; Rainer, G.; Ruíz Peyré, F. y Coy, M. (2013): “Entwicklungstendenzen im ländlichen Raum Nordwest-Argentiniens. Antriebskräfte, Konflikte, Räumliche Konsequenzen", Geographische Rundschau, diciembre 2013, pp. 14-21.

Paz, R. (2006): “¿Desaparición o permanencia de los campesinos ocupantes en el Noroeste Argentino? Evolución y crecimiento en la última década", Canadian Journal of Latin American and Caribbean Studies, vol. 31 (61), pp. 169-197.

Paz, R. y Jara, C. (2014): "Estructura agraria en Santiago del Estero: el proceso de territorialización de las explotaciones campesinas sin límites y su tensión frente al avance del capitalismo agrario", Estudios rurales 1(6), pp. 81-99.

Rivas, A. I. y Natera Rivas, J. J. (2009): "La distribución de la tierra en el Norte Grande Argentino: persistencias y cambios”, Baetica 31, pp. 91-113.

Salvia, A. (coord.) (2011): Deudas sociales en la Argentina posreformas. Algo más que una pobreza de ingresos, Buenos Aires, Biblos, 225 pp.

Smith, N. (2006): "La geografía del desarrollo desigual", en Dunn, B. y Radice, H. (eds.), 100 years of permanent revolution: Results and prospects, Londres, Pluto press, pp.180-195.

Steinberg, C., Gatto, F., \& Cetrángolo, O. (2011): Desigualdades territoriales en la 
Argentina: insumos para el planeamiento estratégico del sector educativo, Naciones Unidas Comisión Económica para América Latina y el Caribe.

Svampa, M. (2012): "Pensar el desarrollo desde América Latina”, en Massuh, G. (ed.), Renunciar al bien común: extractivismo y (pos) desarrollo en América Latina, Buenos Aires, Mardulce, pp. 17-58.

Velázquez, G y Mesaros, G. (2015): "Geografía y calidad de vida en la Argentina", Ciencia Hoy, vol. 24 pp. 27- 31.

Fecha de recepción: 13 de abril de 2016.

Fecha de aceptación: 23 de febrero de 2017. 